"They should visit every patient as soon as admitted, with or without the resident medical officer, and fill up the description-papers for the resident medical officers and physician, and endeavour to obtain from the patient's own statements such particulars as would either throw light on the nature of the case or illustrate its history and origin. Much valuable information is at present lost for want of fuller records of the symptoms on admission.

"The clinical clerks might also divide with the other officers the duties of visiting the wards during the dimner hour of the patients, and the grounds during their hours of exercise. Their duties might cease for the day at four P.M., so as to enable them to reside in London.

"They would of course be willing to be useful in the examination of bodies of patients after death, and in furnishing correct particulars of every kind for the registers, so as to make the statistical tables.fuller and more accurate.

"With such additional facilities, it would then be for the Committee to determine whether the course of clinical instruction should still be limited as to duration, as heretofore, or so extended as to afford three months' instruction, of attendance on which certificates might be given for the students to present to the examiners, at the East India House or elsewhere.

"If such extension should be considered desirable, it would have to be determined what number of students should be admitted at one time, on what days in the week they should visit the Asylum, and in what divisions they should go through the wards.

"Arrangements might be made with reference to all these particulars, if the resident officers would conform to a regular plan of assisting the physician in the regulation of these more frequent visits. The elinical clerks would be furnished by the physician with the names of the patients who were to form the principal subjects of observation and comment; and would be especially charged with the daily record of the progress of and changes in such cases auring the whole course of clinical visits and lectures.

"It appears to me, that if these changes should be approved of, my own usefulness as a teacher, possessing the great opportunities afforded by the Hanwell Asylum, ought, if possible, to be extended to such medical students, in the different school of London, as were attending the practice, not of Hanwel alone, but of any of the large asylums; and this might be done' still with some pectliar advantages to those visiting Hanwell' by my lectures in the Asylum being made more strictly clinical, or consisting chiefly of remarks having direct reference to par ticular cases and occurrences in the wards noticed in the visits; whilst a course of twelve or more lectures, given in London, on the whole subject of insanity, its nature, forms, and treatment, would enable me to impart useful information to all medical pupils desirous of so obtaining it; and to such lectures the medical students attending at Hanwell might have gratuitous admission, and also physicians and surgeons in actual practice.

"As I believe that such opportunities of acquiring a knowledge of the treatment of mental disorders are anxiously desired by many medical students, and by medical men in general, I am willing, recollecting the means of collecting and diffusing useful information which my office as physician to the Hanwell Asylum places at my command, to undertake my part of the duties I have mentioned, hoping at least to be able to perform them for a few years, and not doubting that younger labourers will be found able to succeed me, nnd still further to improve the department of practice and teaching to which I consider my life to be devoted."

This Report was entirely disregarded, and my resignation of the office of physician to the Asylum, which I had often con templated, very soon followed. I trust the physicians oother asylums may be more fortunate in their attempts to establish clinical instruction : but this can only be effected by the aid of an efficient medical staff. Our asylums will then have less resemblance to large workhouses, and become really hospitals for the insane, and schools of valuable instruction.

With a grateful recollection of the numerous services performed by THE LANCET, in the cause of the insane, in the last fourteen years,-I remain, Sir, your very obedient servant, Hanwell, Nov, 1853. J. CoNoLLY, M.D.

\section{MILITIA SURGEONS.}

\section{To the Editor of The Lancer.}

SIR,--Knowing how willingly you aid in removing grievances in the profession, I would endeavour to enlist your sympathies, and those of your readers, for the oppressed militia surgeons.

Probably you know that previous to the year 1829 the sur- geons were retained in the permanent staff, with a pay of, 1 think, 6s. a day, when not embodied, for which they were expected to give attendance, and medicine, to all the members of the staff; also, I believe, to examine the recruits required to supply vacancies in the regiment.

The surgeon is now expected to attend the staff, consisting of the adjutant, non-commissioned officers and drummers, their wives and families, for an allowance of twopence per head a week, which is paltry enough when you consider that the staff is composed of middle-aged men, whose constitutions are enfeebled by previous disease and service-who, being accustomed to serve with a surgeon always at hand, require on every petty occasion his attendance, dispersed, thongh they are, all ver the surface of a large town, their wives still child-bearing.

To supply the requisite number of men to complete our complement against the last training, and not to fill up the vacancies, which are very numerous, days were fixed-never less than two, sometimes four in a week - for the purpose of inspecting and passing volunteers, for which the pay is as follows:-2s. $6 d$. a head for the first four; afterwards the ordinary pay of militia surgeons for a day's service, 11s. 4 ., for which sum I have examined upwards of twnety men in one day: if no man be medically approved, the surgeon receives no pay, though his time has been occupied just the same.

Are these not grievances which call for redress? Will you kindly wield that all-powerful pen of yours-avowedly that of the leading weekly medical journal-in our cause, and the militia surgeons will have reason ever to remember your name with gratitude? I have enclosed my card, according to your custom, but beg to sign myself,

November, 1853.

Verax, a Militia Surgeon.

\section{THE ROYAL COLLEGE OF PHYSICIANS AND THE CHOLERA.}

To the Editor of THE LANCET.

SIR,-Having read a letter in THE LANCET of the 29th of October last, headed "Contagiousness of Cholera," and signed "Edward Wilson, M.D.," I cannot refrain from expressing my astonishment at the reflection cast on the Cholera Committee of the College of Physicians, for having come to the conclusion that cholera is not contagious, or in other words, "that the fear of infection may be practically disregarded." I must also confess my surprise at the eighteen cases brought forward by Dr. Wilson to upset and nullify the result of the deliberations of the committee of the College of Physicians, and the endeavour to prove that they "have fallen into a fatal mistake." As a member of the College, I cannot remain silent and allow. this letter to continue unanswered, and I therefore deny that the cholera committee have fallen into a fatal mistake. I should have preferred seeing the letter in question commented upon by some abler pen, but the subject being one in which every member of the profession is supposed to take great interest, I shall need no apology in my endeavour to bring forward some proofs in favour of the remarks made by the College of Physicians.

When in India, in the medical service of the Hon. East India Company, it was my lot to attend daily at the hospital in Calcutta when cholera was raging there, and I believe I have had very extensive opportunities of forming an opinion respect. ing cholera; but I shall not bring forward any of these cases to support the view taken by the College of Physicans, "that the fear of contagion may be practically disregarded ;" but I shall state the opinions of many of the first men, whose great experience, skill, and talent are well known in every quarter of the civilized world. In Paris, after every consideration had been given to the subject, the medical men, both physicians and surgeons, at the Hotel Dieu, asserted that cholera was not contagious, and signed a resolution to that effect. This resolution was dated 31st March, 1832, and signed by Petit, Husson, Magendie, Honore, Sanson, Gendrin, Recamier, Dupuytren, Breschet, Caillard, and Baillie. I' also find a resolution to the same effect was signed on the 6th of April, 1832, at the Hôpital St. Louis, by the following - viz., Alibert, Biet, Emery, Jobert, Lugol, Monry, Gerdy, and Richerand. Also, on the 30th of April, 1832, the medical men of La Pitie signed a similar resolution: these men were, Serres, Clement, Parent du Chatelet, Lisfrane, Andral, Louis, Bouilland, and Velpeau.

I will now refer to "Hamett's Reports in 1832." Dr. Hamett, who was sent by the government to Dantzic to investigate this subject, states in his official report that 1932 persons of all ages, besides many others, remained constantly in cholera dwellings during the raging of the epidemic, and not one of 
those persons were attacked by cholera; and that 776 cases occurred in various localities, in which there was no trace of contagion. It is also asserted by the British consul at Dantzic (Mr. Gibson) that cholera appeared there withont any reason to suspect that it was within a hundred miles of Dantzic! And it also further appears from the report that there was not the slightest trace of communication with any infected persons or district.

I fear I should occupy too much space were I to prolong this letter, and I will refer those who wish to peruse an interesting report to the three lectures deliverad to the students at St. George's Hospital by Dr. Chambers, physician to the Queen, in February, 1832, one of which appears in THE LANCET of March 3rd, 1832. Dr. Chambers appears there as a noncontagionist. Mr. Grainger has also announced himself a moncontagionist; also Professor Lizars, and Dr. Sanders, of Edinburgh, and others too numerous to mention here.

Yet I admit that the question at issue is far from being satisfactorily decided, and hope that some of your readers may take the opposite side of the question, and give us a résumé of the experience and opinions of the learned members of the profession who are contagionists, as by this, and not by individual opinions, shall we be able to arrive at any satisfactory conclusion.

And in concluding, I must say that I do not think Dr. Wilson justified by his eighteen cases in coming forward and stating that the committee of the College of Physicians have fallen into a fatal mistake; and as to the remark made by Dr. Wilson in his letter, that "had the disease been small pox and not cholera, it would not be doubted for a moment that it was contagious," it is admitted by every member of the profession that small-pox is one of the most contagious diseases on record, and therefore I think Dr. Wilson's remark (that the disease would have been considered contagious had it been small-pox) is quite out of place, and does not bring any weight in the scale.

$$
\text { I am, Sir, yours, \&c., }
$$

Newcastle, Staffordshire, Nov. 1853.
A. F. GOODAY, Member of the College of Physicians, \&o.

\section{NAVAL ASSISTANT-SURGEONS AND THEIR GRIEVANCES}

To the Elitor of THE LANCET.

SIR,-My own individual thanks, as well as the gratitude of every naval assistant-surgeon, are due to you for the noble manner in which from time to time you have advocated the cause (through the medium of THE LANCET) of the junior medical officers in the Royal Navy. That all your efforts to have the position of naval assistant-surgeons improved may be crowned with success must be the sincere desire of every naval medical officer, as well, I am sure, as their professional brethren on shore; and that the Government must and will do something to make the appointment of a junior medical officer on board one of her Majesty's ships of war more tolerable to, and more consonant with, the feelings of a gentleman, and one duly qualified in an honourable profession, is what the profession, both ashore and afloat, must look forward to being sooner or later accomplished.

The grievances of naval assistant-surgeons have so frequently been considered, enumerated, and commented upon in the public papers, that it is needless for me now to recapitulate them, more especially as I now only wish to bring beneath your notice that which, in my humble opinion, and which from my own personal experience, I consider the greatest of all evils connected with a medical appointment in the navyI allude to the non-provision of cabins for assistant-surgeons under three years' service.

In the first place, a cabin is about the only comfort which can be found on board ship, and the truth of this any one who has been exposed to the inconveniences and tumultious noise of a midshipman's berth can vouch for; and putting the plea of comfort entirely out of the question, is it not highly necessary, I may ask, for an assistant-surgeon to have some quiet place to himself, no matter how small, in which he may be able to study without intermution, and not only to keep up the professional knowledge which he has already acquired, but also to make himself acquainted with the improvements which are almost daily takino place in medical literature? Is it not highly necessary that he shonll be allowed this privilece, not only for his own improvement, but also for the benefit of those upon whom he has to exercise his professional skill? and yet how few-how very few-junior medical officers are indulged with the luxury of a cabin! Subterfuges in themselves both

frivolous and ignoble are frequently had recourse to, in order to deprive an assistant-surgeon in the navy of the cabin he is entitled to, even after his three years' servitude; while the idea of allowing one to a young medical officer who has not served the above period is not for a moment entertained by many commanding officers, even though there may be a spare cabin in the ship for which there is no use, and of this I have myself experienced an instance, which, with your permission, I should wish to lay before my professional brethren, as well as the public at large.

Not many months ago, I was appointed to a 90 -gun line-of. battle ship at Portsmouth, in the room of an assistant-surgeon who, fortunately for himself, had served beyond the probationary period of three years, and had therefore enjoyed the luxury of a cabin, which, in my innocence, I vainly imagined would be bestowed upon me upon joining the ship; but the utter folly of my supposition was too plainly made manifest to me upon speaking abont the subject to the captain. Upon my venturing to solicit the vacant cabin, $T$ was informed that the service did not allow me one under three years' standing, and that "they were strictly service people on board that ship, and therefore conld not for a moment entertain the idea of giving it to me."

This was all very fair, indecd, and had the gallant captain acted up to what he said, I could not have complained, but unfortunately I soon discovered that his ideas of the service were not only original, but also were not very favourab!e to medical officers, as he bestowed the vacant cabin on a clerk, an officer to whom a cabin is not allowed by the service, and who, moreover, ranks beneath an assistant-surgeon!

Some short time afterwards the clerk left the ship for another appointment, and the cabin again became vacant, when, rather than bestow it upon a medical officer, it was hurriedly given to a mate, who occupied it until his promotion, which took place in a few weeks' time. The unfortunate cabin was then again untenanted, when, as there was no other pet clerk or mate, and as it conld not very well be bestowed on a midshipman, it was allowed to remain unoccupied rather than that an assistant-surgeon should become its possessor. All this occurred to myself at a very recent date, and in a ship where ample accommodation would not have been at all materially diminished by the loss of a single cabin.

$\mathrm{Had} I$ in any way have rendered myself unpopular in the ship, or disagreeable to the captain before soliciting the cabin, it would have altered the case I grant; but this, I am happy to say, was not the case, as my messmates can testify to the one, and, as the other could not have occurred as coming straight from a naval hospital to the ship, the captain had not had an opportunity of even seeing me before the conversation alluded to above took place.

This one instance will serve to show the strong feeling which exists among the executive officers of the Royal Navy against the junior medical officers of the same service; and I can only say, in conchision, that the present dearth of candidates for the appointment of assistant-surgeons in the navy is about the best argument which can be nsed with the Government, in order that the position of that class of officers may be speedily improved, and is also hailed by every young medical man in the service as the harbinger of better days for themselves and their professional brethren afloat.

Should you deem this letter worthy of a place in your journal, you will, by inserting it in your columns, much oblige

Noveraber, 1853. Yours obediently,

\section{THE NEW VACCINATION ACT. To the Editor of The LANCET.}

SIR,-The enclosed letter was received by the registrar of this district in consequence of my refusing to give (gratuitously) duplicate certificates. In every case I have given the necessary certificate to the parent, or the person having the care of the child for their protection, but have refused to deliver the duplicate to the registrar.

Will you have the kindness to give me your opinion whether the Registrar-General is correct in stating that medical practitioners are legally bound to deliver a duplicate to the registrar of the district. I am, Sir, your obedient servant,

Brighousc, near Falifax, Nov. $18 \overline{3} 3$

\section{[COPY.]}

ROBERT FARRER,

General Register Offee, Nor, 16, 1853.

SIR, - With reference to your letter of the I 1 th inst., I am directed by the Registrar.General to inform you that $\mathrm{Mr}$. 